\title{
A RECEPÇÃO DO PENSAMENTO DE ROGER BASTIDE NO BRASIL ${ }^{1}$
}

\author{
Maria Lúcia de Santana Braga
}

Resumo. O artigo trata da recepção do pensamento de Roger Bastide no Brasil durante quase duas décadas, de 1938 a 1954. Bastide, como professor, pesquisador e pensador, estabeleceu relações diversas com seus contemporâneos e alunos. Aqui, com objetivo de compreender o impacto e a importância das idéias bastidianas no País, analisaremos as relações estruturadas com quatro ex-alunos e cientistas sociais brasileiros: Antônio Cândido, Florestan Fernandes, Gilda de Mello e Souza e Maria Isaura Pereira de Queiroz.

Palavras-chave: Roger Bastide, pensamento social, Antônio Cândido, Florestan Fernandes, Gilda de Mello e Souza e Maria Isaura Pereira de Queiroz.

\section{Introdução}

A análise da repercussão e da recepção do pensamento de Roger Bastide no Brasil, principalmente na primeira geração de cientistas sociais brasileiros, consiste em aspecto ainda pouco explorado na história das ciências sociais no País. Nesse artigo, pretendemos abordar

Maria Lúcia de Santana Braga é socióloga e mestre em Sociologia, doutoranda no Programa de Pós-graduação em Sociologia da Universidade de Brasília (UnB), pesquisadora do Núcleo de Políticas Científicas e Tecnológicas (NPCT), da UnB. Desenvolve estudos na área de meio ambiente, sociologia da cultura e pensamento social no Brasil. Organizou com Laura Maria Goulart Duarte o livro Tristes Cerrados: sociedade e biodiversidade, publicado pela Editora Paralelo 15 em 1998. 
esse percurso por meio do estudo da relação estabelecida entre Bastide e quatro de seus ex-alunos.

Assim como os outros professores franceses que vieram para o Brasil na década de 30, Bastide contribuiu de forma efetiva para a estruturação do ensino universitário nos moldes existentes na Europa. O papel desempenhado por Bastide nesse processo foi marcante no ensino e na pesquisa. Durante a "Semana Roger Bastide" ocorrida em 1976², Oracy Nogueira (1978) lembrou que, até aquele momento, não havia sido feito um estudo sistemático do conjunto da obra de Roger Bastide, a qual foi produzida durante mais de cinco décadas, abarcando desde os anos 20 até os anos 70. Acreditamos que essa lacuna já foi preenchida em grande parte pelas várias análises de Maria Isaura Pereira de Queiroz (1977, 1978, 1983, 1989 e 1993), pelos trabalhos de Charles Beylier (1977), Claude Ravelet (1978), Denise Dauty (1985), Maria Lúcia de Santana Braga (1994) e Fernanda Peixoto (2000).

Nogueira também apontou a necessidade de identificar a recepção de Roger Bastide em seus discípulos diretos e indiretos. Como discípulos diretos figuram, segundo ele, os seus ex-alunos, e como discípulos indiretos estão os que não foram seus alunos mas que tiveram algum tipo de contato e sofreram a influência das idéias bastidianas. Nogueira admite que a longa convivência entre professores de tradições diversas, em especial a européia e a norte-americana, possibilitou uma formação diferenciada aos cientistas sociais brasileiros. Em que medida esses cientistas se tornaram herdeiros das tradições representadas pelos pensadores brasileiros e dos novos professores lotados na USP? Qual foi o papel desempenhado por Roger Bastide na formação dos novos cientistas sociais?

Bastide permaneceu longo período no Brasil, onde cumpriu uma trajetória intelectual em muitos aspectos distinta da dos demais professores, pois já era um pensador maduro quando chegou aqui e publicou em português boa parte da sua produção intelectual elaborada no País. O que interessa mostrar nesse artigo é que Roger Bastide cumpriu um papel primordial na formação dos novos cientistas sociais brasileiros, cujo enfoque primou pelo pluralismo e destinou-se a formar "homens de cultura", segundo explicita Mariza Peirano (1992).

Esse espírito pluralista, já predominante na USP nas décadas de 30 e 40, acentuou-se nos alunos formados por Bastide e por outros 
professores. As primeiras gerações oriundas da USP, que puderam desenvolver seus interesses por diferentes áreas como a literatura, a arte, a política e o folclore, ainda estavam imbuídas do estilo literário presente nos pensadores brasileiros das décadas anteriores, mas já conjugado com o conhecimento de novas teorias e métodos, conforme nos lembra Antônio Cândido: "Eu acho que a minha geração foi a última em que ainda a literatura aparecia como um must. Antes, a medicina precisava se apresentar com roupa literária, o direito, também; a sociologia, para se apresentar, tinha que se apresentar como Os Sertões."

Pluralismo, que em certa medida, permanece nas ciências sociais brasileiras como uma característica positiva, segundo especifica Mariza Peirano:

É justamente porque tal fato se deu que hoje podemos reconhecer que os ensinamentos deixados por Roger Bastide, Emilio Willems e pelos professores franceses de filosofia nas décadas de 30 e 40 não desapareceram. Esta influência permanece conosco até hoje, e a reconhecemos quando presenciamos no nosso dia-a-dia acadêmico questões que se colocam sobre trabalhos de sociólogos, antropólogos, cientistas políticos e historiadores: aqui é o antropólogo 'que não é bem antropólogo' - é mais um 'sociólogo desenvolvimentista'; ali o cientista político faz é história mesmo; lá é o historiador com pendores antropológicos. (Peirano, 1992, p.46)

Esse espírito crítico e plural foi reforçado pelas missões estrangeiras que traziam consigo a tradição durkheimiana, mas já mediada por outras influências teóricas e metodológicas. Bastide e Fernando Azevedo, em artigo sobre o ensino de sociologia em São Paulo, se colocaram contrários às análises geralmente feitas sobre a USP como representante da sociologia durkheimiana e a Escola Livre de Sociologia e Política, da sociologia norte-americana. Para eles, esta era uma avaliação simplista, que escondia a riqueza dos métodos e das teorias sociológicas representadas pelas duas escolas naquele período. ${ }^{4}$

É, assim, que essa primeira geração se voltou para o estudo de temas diversos, nos quais o elo unificador consistia no espírito crítico que os professores, particularmente Bastide, procuravam estimular. Antônio Cândido se deteve na literatura enquanto Florestan Fernandes 
se dedicou em seus primeiros estudos à análise do folclore e depois das sociedades indígenas. Gilda de Mello e Souza elaborou importante estudo sobre a estética e a moda, Lourival Gomes Machado fez vários estudos capitais sobre o barroco, Ruy Coelho também se interessou pela literatura e Maria Isaura Pereira de Queiroz pela sociologia religiosa, em especial pelo messianismo, entre outros ex-alunos de Bastide. ${ }^{5}$ Ou seja, temas diversos que refletiam a coexistência de influências ainda dos pensadores brasileiros do século passado e dos novos pensadores estrangeiros unidos por uma mesma abordagem de cunho pluralista.

Pretendemos aqui ver de que modo essas idéias foram trabalhadas pelos novos cientistas sociais brasileiros, particularmente analisando a importância de Bastide nesse processo. Para isso, procederemos à análise da trajetória de quatro cientistas sociais que melhor exemplificam a recepção do pensamento do sociólogo francês no Brasil: Antônio Cândido, Florestan Fernandes, Gilda de Mello e Souza e Maria Isaura Pereira de Queiroz.

A escolha desses quatro cientistas sociais ocorreu basicamente porque eles representam, em nosso entender, dois tipos principais de relações estabelecidas por Roger Bastide com os seus alunos. O primeiro tipo de relação compreende muito mais uma espécie de colaboração e interlocução permanente presente em especial em Antônio Cândido e Florestan Fernandes. O segundo tipo de relação se define em certa medida pela dicotomia mestre-discípulo encontrada em Gilda de Mello e Souza e Maria Isaura Pereira de Queiroz. Os testemunhos colhidos deixaram evidente essa diferenciação, conforme nos atesta Florestan Fernandes: "Quem era realmente discípulo de Bastide não era o professor Antônio Cândido mas era a professora Gilda de Mello e Souza, esposa dele, especialmente no campo da sociologia estética. E a outra pessoa é a Maria Isaura Pereira de Queiroz no campo religioso e também no folclore e outros assuntos" (Depoimento concedido à autora em 03/05/1994).

Gilda de Mello e Souza, em seu depoimento, também esclarece as diferenças entre a sua trajetória e a de Florestan Fernandes: "Florestan foi mais um colaborador. Eles fizeram vários trabalhos juntos, coisa que eu nunca fiz. Eu não. Eu fui discípula mesmo dele sobretudo no momento que fiz a minha tese" (Depoimento concedido à autora em 26/05/1994). 
Essa distinção que aqui queremos deixar clara é um recurso que permite analisar trajetórias tão ricas e diversas como as de Antônio Cândido, Florestan Fernandes, Gilda de Mello e Souza e Maria Isaura Pereira de Queiroz. Deixaremos de lado muitos aspectos relevantes, pois restringiremos nossa análise à influência de Bastide em suas trajetórias intelectuais e acadêmicas. De forma geral, trataremos, nos tópicos a seguir, principalmente da relação estabelecida entre Roger Bastide e esses quatro ex-alunos, procurando esclarecer o papel desempenhado pelo sociólogo francês como pensador, professor e pesquisador. Privilegiaremos, portanto, os momentos iniciais dessa longa relação: os primeiros contatos, os cursos realizados na USP, as pesquisas feitas nesse período, o convívio dentro e fora da universidade, os temas e métodos mais relevantes, a diferença de Bastide em relação aos outros professores franceses e o estilo de ciências sociais praticado, que se delineia a partir desta relação.

Nesse sentido, preferimos adotar a ordem cronológica em nossa análise a partir da chegada de Roger Bastide ao Brasil. Ou seja, conforme foram sendo estabelecidos os contatos: Gilda de Mello e Souza, Antônio Cândido, Florestan Fernandes e Maria Isaura Pereira de Queiroz.

\section{Gilda de Mello e Souza: a visão estética ${ }^{6}$}

Gilda de Mello e Souza iniciou o curso de ciências sociais na USP em 1937. Naquele momento, o professor que ocupava a Cadeira de Sociologia I da Faculdade de Filosofia, Ciências e Letras da USP era Claude Lévi-Strauss. Gilda foi aluna do professor Lévi-Strauss por seis meses quando então este rompeu o contrato com a universidade. Em sua substituição veio Roger Bastide que assumiu a Cadeira em 1938. Gilda de Mello e Souza e Antônio Cândido relatam que houve um mal-entendido nesse período e uma certa resistência à vinda de Bastide para ocupar a Cadeira de Sociologia I. Para Antônio Cândido:

Eu sei que houve uma coisa muito desagradável. O Lévi-Strauss era professor aqui. Um certo momento e antes do contrato dele acabar ele foi embora. Não foi recontratado. Ele acusava dois colegas dele de causadores da ida dele: o prof. Paul Arbousse-Bastide e o prof. Roger Bastide. O Bastide não tinha nada com isso. O prof. 
Arbousse-Bastide podia ter tido porque eles viviam brigando. Não posso dizer que tenha havido alguma coisa. Roger Bastide veio substituí-lo. Como Roger Bastide veio substituí-lo, Lévi-Strauss ficou cismado que o Roger Bastide tinha... Parece que ele ficou muito contra o Bastide.

Gilda de Mello e Souza complementa sugerindo que essa dificuldade também ocorreu devido à rejeição inicial dos alunos:

Tem uma coisa que talvez tenha facilitado essa opinião. Quando o Roger Bastide chegou, Lévi-Strauss tinha na faculdade um grupo de alunos entusiasmados por ele. Ele era um professor seco, era um professor nada brilhante do ponto de vista francês. Quer dizer, era outro brilho que ele tinha. Mas ele tinha oito ou dez alunos fanáticos por ele. E esses alunos resistiram muito ao Roger Bastide no princípio. Depois não, mas no princípio...

Mais tarde, o próprio Lévi-Strauss reconheceu que Roger Bastide não havia tido qualquer interferência em relação à sua saída da universidade, tendo inclusive escrito a ele para desfazer o mal-entendido, segundo Antônio Cândido. ${ }^{7}$

A resistência inicial ao novo professor logo se desfez como bem coloca Gilda de Mello e Souza devido principalmente à personalidade de Bastide. O perfil traçado é de um professor que tinha um profundo respeito pelos alunos, deixando os seus interesses e capacidades aflorarem. Para Souza:

Então ser aluna de Roger Bastide significa uma coisa muito especial. Eu acho que significa sobretudo você ter a liberdade de encontrar a sua tendência profunda. A minha, por exemplo, naquele momento era muito especial, muito diferente da Maria Isaura. A Maria Isaura era uma aluna de outro tipo, o Antônio Cândido era um aluno de outro tipo e eu era uma aluna de outro tipo. Então, ele tinha essa acuidade extraordinária de respeitar aquilo que a pessoa era, independente de ser discípulo dele.

No caso de Gilda de Mello de Souza, a diferença estabelecida se refere à sua experiência anterior na ficção, elemento que não estava presente nos outros alunos daquele período. Bastide, de imediato, identificou-se com isto devido ao seu próprio interesse pela literatura e também pela sua experiência anterior. ${ }^{8}$ 
A capacidade e a sensibilidade em perceber e respeitar as especificidades de seus alunos também se refletiram nos cursos realizados na USP. Bastide combinava seu próprio interesse em conhecer de forma profunda o país onde estava com os diversos interesses de seus alunos. Gilda de Mello e Souza reforça esse traço da personalidade do pesquisador e professor Bastide ao lembrar o seu respeito pelos alunos, pessoas e situações que procurava observar e analisar.

Após concluir o curso de ciências sociais em 1939, Gilda de Mello e Souza se tornou assistente de Roger Bastide na Cadeira de Sociologia I. As suas relações se estreitaram nesse período, tendo inclusive Gilda e Antônio Cândido traduzido vários artigos, ensaios e livros de Bastide. ${ }^{9}$ Gilda especifica, que além dos cursos feitos com Bastide, o contato constante com o pensamento do mestre francês, por meio de seus artigos sobre os mais diversos assuntos e também como sua assistente nas aulas, produziram uma influência profunda em sua orientação intelectual que se alargou de forma definitiva no momento da elaboração da tese de doutorado.

Gilda nos revela como foi a relação com Bastide nesse momento:

Quando foi na ocasião de eu fazer a minha tese ele fez comigo provavelmente o que fazia com outros alunos dóceis. Não com Florestan porque era um aluno com uma personalidade muito forte. (...) Ele me deu uma relação muito grande de temas de tese. Ele dava o tema e dizia: isto tem essa qualidade e tem este problema. Que era problema às vezes de bibliografia, que às vezes levando em conta o temperamento que dependia de muita pesquisa em arquivo, coisas desse tipo. E entre estes assuntos ele pôs a moda. Não fui eu. Eu digo isso porque acho importante para mostrar. Ele não poria para o Florestan provavelmente, mas para mim ele pôs. Ele pôs a moda e eu vi na relação uma adesão maior a assuntos desse tipo porque ele estava pensando em mim.

Podemos notar que Bastide tinha em conta o interesse e a personalidade de sua aluna. Depois de ter escolhido a moda como tema de sua tese, Gilda conta que Bastide, então, combinou ter sessões periódicas de orientação com ela. No entanto, Gilda preferiu adotar outro tipo de procedimento que em seu entender decorreu da sua necessidade naquele momento de ter certa independência na etapa inicial da elaboração da tese. Conforme Gilda, essa necessidade foi fruto de 
sua relação dependente desde a infância com pessoas muito fortes e de grande prestígio como Mário de Andrade de quem era prima.

A sua proposta de trabalho foi aceita por Bastide. Assim, Gilda elaborava os capítulos e entregava para a apreciação de Bastide que fazia uma série de considerações e sugestões para a sua melhoria. Então, a tese "foi feita com uma interferência dele muito cautelosa. E, portanto, me dando uma liberdade muito grande. E era uma tese completamente fora do esquadro naquela época." Publicada na Revista do Museu Paulista em 1950, a tese A Moda do Século XIX pode ser considerada um trabalho precursor ao tratar a moda como fato cultural e social. ${ }^{10}$

Preocupada em analisar o fenômeno da moda mediante a sua relação com a estrutura social, na qual as mudanças estão intimamente ligadas às transformações mais vastas da sociedade, Gilda de Mello e Souza optou por realizar estudo mais aprofundado sobre alguns aspectos como a divisão sexual e a divisão em classes do que um estudo mais panorâmico. Para isto, utilizou fontes diversas não se atendo somente aos estudos mais acadêmicos, mas também lançando mão de outras fontes como fotografias, pinturas, gravuras, crônicas e romances da época que forneciam um quadro completo da moda.

Bastide, como orientador, apoiou inteiramente o trabalho de sua aluna. Gilda reforça esse apoio ao relatar que em certo momento ela e Antônio Cândido ficaram em dúvida se o que estavam fazendo era sociológico. Bastide simplesmente respondeu: "Não existe isso de muito sociológico, o que existe são trabalhos bons, bem feitos ou mal feitos."

É explícita a extrema sensibilidade de Bastide para temas e métodos que no período não eram ainda considerados dignos de atenção por parte dos cientistas sociais e como procurava incentivar nos seus alunos essa mesma diversidade e sensibilidade. Para Gilda de Mello e Souza, isto fica bastante evidente ao comparar a trajetória de Bastide com a de Lévi-Strauss que dedicou seus estudos a temas bem precisos. Apesar de ser um dos pensadores fundamentais do século XX, Lévi-Strauss teve uma grande dificuldade em entender a extrema diversidade da cultura brasileira.

Ele poderia entender bem o índio que era uma cultura completamente diversificada mas uma cultura à cavaleiro de várias influências como a brasileira da indígena, da africana, da portuguesa e uma paisagem tão diferente da Europa às vezes que ele opinou, 
opinou mal. Então, não havia no Lévi-Strauss esse mimetismo, digamos essa capacidade de se adaptar a uma realidade profundamente diferente seja ela visual, literária ou de identidade. No "Bastidinho" havia.

\section{Antônio Cândido: a literatura como opção ${ }^{11}$}

Antônio Cândido ingressou na Universidade de São Paulo em 1939 e freqüentou simultaneamente os cursos de ciências sociais e de direito. Um pouco depois, abandonou o curso de direito no quinto ano, dedicando-se inteiramente às ciências sociais. Na Faculdade de Filosofia, Ciências e Letras, Antônio Cândido tornou-se aluno do professor Roger Bastide logo no primeiro ano.

Em seu depoimento, Antônio Cândido de antemão define a sua relação com Bastide: "Com o professor Roger Bastide, eu posso dizer que tive relações em dois planos: como aluno e como interlocutor. Não posso dizer que tenha sido propriamente amigo dele. A diferença de idade era muito grande. Mas nós tínhamos uma relação muito afetuosa."

Desde o primeiro ano, Antônio Cândido e Bastide começaram a se encontrar nos corredores da faculdade. Para Antônio Cândido, em uma avaliação sincera, o primeiro curso feito com Bastide não foi muito útil, pois este estava muito preocupado com os problemas metodológicos e durante todo o ano trabalhou com a monografia social da Escola de Le Play. No entanto, os encontros fora das aulas ocorriam freqüentemente, quando conversavam sobre literatura, história e casos pitorescos.

Já no segundo ano, em 1940, Bastide ofereceu o curso sobre sociologia da arte que se transformou, em 1945, no livro Arte e Sociedade. Antônio Cândido considerou-o admirável. Também, nesse mesmo ano, Bastide tratou do barroco brasileiro em outro curso. Segundo Antônio Cândido, foi a primeira vez que se ouviu falar de tal temática. Gilda de Mello e Souza, em seu depoimento, também especificou que foi Bastide o primeiro a chamar a atenção para o barroco brasileiro. Ressalta, inclusive, que as suas idéias sobre o barroco influenciaram enormemente as avaliações posteriores como as de Lourival Gomes Machado que foi também seu aluno.

No terceiro ano, Bastide aceitou uma sugestão de Antônio Cândido e ofereceu um curso sobre a sociologia dos mitos. Tratou primeiro da 
literatura existente sobre os mitos para depois analisar os mitos brasileiros. Nesse sentido, Antônio Cândido considera que foi Bastide o primeiro a abordar o mito do Aleijadinho como uma criação ou uma representação coletiva. Gilda de Mello e Souza acrescenta que Bastide antecipou essas considerações sobre a criação do mito do Aleijadinho ao apontar os sintomas desse processo como a enorme dificuldade que Aleijadinho tinha a vencer sem as mãos para realizar as suas esculturas, o que Bastide considerava impossível de ter sido feito.

Ao contrário de várias avaliações correntes, Antônio Cândido ressalta que havia a preocupação constante de Bastide e dos outros professores franceses com a pesquisa. $\mathrm{O}$ incentivo constante aos alunos para a realização de pesquisas sempre esteve presente. Cândido, por exemplo, teve que realizar vários trabalhos de aproveitamento durante os três anos de curso. No primeiro ano, realizou uma pesquisa sobre a mortalidade negra infantil no Vale do Paraíba na segunda metade do século XVIII no Arquivo Público do Estado de São Paulo. No segundo ano, fez um trabalho sobre a evolução do gosto musical em São Paulo a partir de entrevistas, fichas da cinemateca e análise de programas de concertos. Nesse mesmo ano, também foi realizada uma pesquisa sobre os resquícios do barroco em São Paulo. ${ }^{12}$

Ao terminar o curso de ciências sociais em 1941, Antônio Cândido havia se tornado um interlocutor de Bastide, discutindo sobre sociologia e literatura, entre outros temas. A partir de 1942, tornou-se primeiro assistente da Cadeira de Sociologia II, na Faculdade de Filosofia, onde permaneceu até 1958. Em 1945, Antônio Cândido defendeu a tese de livre docência em literatura brasileira com o trabalho $O$ Método Crítico em Sílvio Romero. Bastide, então, insistiu com ele para fazer a tese de doutoramento em ciências sociais.

Nesse período, Antônio Cândido salienta que havia uma preocupação por parte de muitos alunos com a definição dos campos de investigação de cada ciência. Ele se debatia com esse problema em relação à sua tese. Bastide, no entanto, não tinha essas distinções como essenciais.

Ao contrário, em nenhum momento em sua obra Bastide se prendeu a essas especializações. Para Antônio Cândido, isto foi fundamental na definição de seus próprios interesses e fundamentalmente na sua carreira intelectual entre permanecer na sociologia ou mudar para a literatura. 
Depois, quando eu senti já era assistente de sociologia e fazia crítica literária. Eu o consultei: eu estava com vontade de deixar a sociologia. E o meu chefe que era o professor Fernando de Azevedo, muito meu amigo, não queria ouvir falar nisso. Eu consultei o professor Bastide e foi muito importante para mim. Professor Bastide: vou fazer uma pergunta ao senhor. O senhor acha que funciona melhor em sociologia ou em literatura? Fiquei um pouco sem graça porque eu era assistente de sociologia e se eu digo que não funcionava em sociologia ele podia ficar magoado. Ele pensou um pouco e disse: acho que o seu lugar é na literatura. Isso me ajudou muito. Ajudou muito.

Antônio Cândido elaborou a tese de doutoramento em ciências sociais Os Parceiros do Rio Bonito, defendida em 1954. Roger Bastide fez parte da banca de Antônio Cândido antes de voltar definitivamente para a França. Quatro anos depois, em 1958, Antônio Cândido se transferia para a literatura, tornando-se professor de literatura brasileira na Universidade Estadual Paulista (Unesp).

Roger Bastide, portanto, teve um papel fundamental na trajetória intelectual de Antônio Cândido. O constante diálogo entre eles propiciou uma aproximação muito grande no período em que Bastide esteve no Brasil e também após o seu retorno, apesar de ter sido menos freqüente. Segundo Antônio Cândido, o perfil do pensador e do homem Bastide era marcadamente o de um humanista e pesquisador que não descansava, sempre interessado em todos os temas, anotando e produzindo trabalhos. ${ }^{13}$ Dessa forma, a trajetória intelectual de Antônio Cândido não pode ser compreendida sem referências a Bastide.

Para mim pessoalmente a coisa mais importante tenha sido o fato de que o professor Bastide era um homem que cuidava muito da literatura. Era bom crítico literário, ele era muito bom crítico literário. (...) Posso dizer que tive na faculdade duas influências fundamentais que foram sobretudo o meu professor de filosofia Jean Maugué que é um homem que não fez nome e o professor Roger Bastide.

As concepções de Bastide sobre a arte e a literatura baseadas em uma sólida formação sociológica realizaram uma combinação que levou à elaboração de um “(...) critério dominante, sempre ressaltado nas conversas, era emitir juízos de realidade, não de valor, afastando o problema de avaliar méritos para ficar nas verificações objetivas." 
(Cândido, 1993, p.99). Isto teve uma grande influência em seus alunos e interlocutores mais diretos.

O próprio Antônio Cândido reconhece de maneira clara em vários momentos: "Eu, pessoalmente, lhe devo muito e às vezes me surpreendo, relendo a anos de distância algum escrito dele, ao verificar até que ponto certas idéias que julgava minhas são na verdade não apenas devidas à sua influência mas já expressamente formuladas por ele" (Cândido, 1993, p.99-100).

A linha de interpretação de Bastide, baseada no tratamento objetivo dos fenômenos artísticos à procura dos determinantes sociais e ao mesmo tempo da influência da arte sobre a sociedade, foi incorporada por Antônio Cândido que explicita à propósito do ensaio de Bastide sobre Machado de Assis:14 "Quando o reli há tempos, depois de muitos anos, senti que foi uma das fontes de várias idéias que estão na base da minha concepção de literatura brasileira. Os pontos de vista se incrustavam de tal modo na minha mente, que perdi a noção do quanto lhe devo" (Cândido, 1993, p.105).

\section{Florestan Fernandes: a vocação científica}

O próprio Florestan Fernandes nos chama a atenção para o domínio da tendência intelectualista que apenas compreende como "os anos de formação" os anos de socialização acadêmica, em especial aqueles referentes ao ensino de nível superior. Florestan Fernandes não concorda com essa concepção pois, conforme a sua própria formação, os anos anteriores detêm uma importância fundamental:

Eu nunca teria sido o sociólogo em que me converti sem o meu passado e sem a socialização pré e extra-escolar que recebi, através das outras lições da vida. Para o bem ou para o mal - sem invocarse a questão do ressentimento, que a crítica conservadora lançou contra mim - à minha formação acadêmica superpôs-se a uma formação humana que ela não conseguiu distorcer nem esterilizar. Portanto, ainda que isso pareça pouco ortodoxo e antiintelectualista, afirmo que iniciei a minha aprendizagem sociológica aos seis anos, quando precisei ganhar a vida como se fosse adulto e penetrei, pelas vias da experiência concreta, no conhecimento do que é a convivência humana e a sociedade. (Fernandes, 1977, p. 142) 
Os anos de socialização anteriores à entrada de Florestan Fernandes na universidade são elementos que não podem ser descartados no entendimento de sua trajetória e na descoberta de sua vocação como acadêmico. Eliane Veras Soares (1997), por exemplo, nos aponta a necessidade de ter em conta essa socialização inicial para a compreensão da trajetória posterior de Florestan Fernandes no campo político e científico. ${ }^{15}$ Três elementos foram fundamentais na formação de Florestan Fernandes e que o levaram a superar inúmeras barreiras e a ingressar na universidade.

(...) a socialização básica recebida na casa da madrinha e na escola primária, que lhe forneceu os rudimentos elementares para sua formação como autodidata; a experiência de vida na rua e no trabalho na qual descobriu o significado do caráter humano; e, por fim, a transformação operada no Ginásio Riachuelo e no emprego na Nova Terápica que o incluiu no 'mundo dos homens'. (Soares, 1997, p.26-27)

Em 1941, Florestan Fernandes fez a seleção e foi aprovado para o curso de ciências sociais da Faculdade de Filosofia da Universidade de São Paulo. O curso de ciências sociais foi escolhido basicamente porque era de meio período e também porque habilitava Florestan para o magistério secundário. Em seu depoimento à Eliane Veras Soares (1997), Florestan salientou três fatores que definiram a sua vida acadêmica:

a) as relações intelectuais e de amizade com Antônio Cândido e Fernando de Azevedo, que o convidou para ser o segundo assistente na Cadeira de Sociologia II, onde veio a iniciar a sua carreira docente; b) o fato da Faculdade de Filosofia funcionar, naquele período, com um forte espírito de grupo no qual os jovens talentos eram coletivamente reconhecidos e estimulados, o que Florestan denominou de 'reconhecimento prematuro do valor intelectual'; c) o seu reconhecimento por parte do público, através da publicação de artigos nos jornais $O$ Estado de São Paulo e Folha da Manhã e na revista Sociologia, reconhecimento esse que se refletiu favora-velmente no universo acadêmico. (Soares, 1997, p.31)

Inferimos que nesses três fatores que detêm tal relevância na trajetória intelectual de Florestan está presente, de uma forma ou de outra, Roger Bastide. É o que veremos a seguir. 
Florestan Fernandes foi aluno de Bastide durante os quatro anos de curso. No primeiro ano, as relações somente se estabeleceram no plano aluno/professor. Em 1941, além de Lavínia Costa Vilela, eram assistentes de Bastide: Lucila Hermann e Gioconda Mussolini. Para o curso oferecido sobre o método monográfico de Le Play, Florestan elaborou um trabalho de aproveitamento sobre o folclore em São Paulo. Após um extenso levantamento, Florestan teve condições de propor uma abordagem original do folclore, o que não foi bem aceita pela primeira assistente de Bastide, Lavínia Vilela, mas mesmo assim lhe deu nota nove. ${ }^{16}$

Florestan não se contentou com a menção recebida e entrou em contato com o professor Bastide. Bastide não tinha conhecimento do trabalho e convidou Florestan para ir à sua casa conversar. Após uma longa conversa, na qual Bastide ficou a par inclusive que Florestan trabalhava além de estudar, o sociólogo francês fez um convite: ${ }^{17}$

Nós vamos sair junto. O senhor tem tempo? Eu falei: tenho. Ele foi comigo até o Sérgio Milliet que era crítico literário do Estado de São Paulo. Dirigia o jornal, a família Mesquita estava fora do Brasil por causa do Estado Novo. O Sérgio Milliet nos recebeu, ele era muito amigo de Bastide, nos recebeu na hora sem formalidade. Aí, eu descobri o que o Bastide queria. O Bastide foi lá pedir um emprego para mim. Queria que eu largasse o emprego que eu tinha e ter algo mais compatível com o trabalho que eu estava fazendo na universidade. O senhor Milliet disse: olha, Florestan, me tratando com intimidade, você quer um conselho meu? Se você quer um emprego eu arranjo já, mas lhe dou um conselho: não aceite esse emprego. Você vai se burocratizar, você vai passar a vida aqui dentro. A outra solução é que você escreva uns artigos para $O$ Estado de São Paulo. (Depoimento concedido à autora em 03/05/1994)

Florestan aceitou o conselho e tornou-se colaborador de $O$ Estado de São Paulo. Os três primeiros artigos trataram do negro na tradição oral, aproveitando o material coletado na pesquisa sobre o folclore. Pouco depois, Florestan Fernandes também foi convidado a colaborar no jornal A Folha da Manhã. O prestígio e o reconhecimento decorrentes da ajuda de Bastide, Florestan reconhece de antemão: "Escrever em jornal como colaborador naquela época era altamente prestigioso. Quando ele pediu emprego ao Sérgio Milliet, eu tive vontade de me 
enfiar por baixo de um tapete, envergonhado. Ele, com toda ingenuidade, pediu na minha frente. Então, esse é o primeiro contato que eu tive com ele. Depois a convivência foi se estreitando" (Depoimento concedido à autora em 03/05/1994).

Em seguida, Bastide apresentou o trabalho de Florestan para publicação na Revista Sociologia, cujo coordenador era o professor Emílio Willems. Vários artigos saíram publicados pela revista sobre a socialização da criança no grupo infantil. Assim, em apenas dois anos, Florestan se tornou um estudante de reconhecida capacidade intelectual e com estreitas ligações com vários professores, entre eles Roger Bastide. ${ }^{18}$ Florestan reconhece que, sem a contribuição de Bastide, teria sido mais difícil: "Logo de início a sorte me ajudou e o Bastide está no centro disso tudo porque ele foi o professor que abriu as portas para esse vasto desdobramento de ocorrências que seriam inexistentes sem a colaboração dele" (Depoimento concedido à autora em 03/05/1994).

Ao terminar o curso em 1944, Florestan Fernandes aceitou o convite do professor Fernando de Azevedo para ser o seu segundo assistente. Na Cadeira de Sociologia I, ocupada por Bastide, não havia vagas, o que ocorreu somente mais tarde com a saída de Lavínia Vilela. ${ }^{19}$ Florestan, então, ficou sendo ao mesmo tempo assistente de Fernando de Azevedo e Roger Bastide durante um período. Bastide, na indicação de Florestan para ocupar a vaga, deixou bem claro que a única pessoa que poderia substituí-lo quando de seu retorno à França seria Florestan Fernandes. Segundo Florestan, o professor Fernando de Azevedo não abriu mão de sua colaboração e ele teve que ficar durante algum tempo com uma carga de trabalho pesada, até conseguir se dedicar somente à Cadeira de Sociologia I.

Merecem destaque, no estreitamento da colaboração entre Roger Bastide e Florestan Fernandes, as pesquisas sobre as relações raciais no Brasil. Desde os anos 40, Bastide já vinha estudando o negro e as suas manifestações religiosas e artísticas. Em 1950, a Unesco solicitou a Bastide uma ampla pesquisa sobre a situação do negro em São Paulo. Florestan foi convidado por Bastide a se incorporar no projeto, o que levou a uma mudança na orientação intelectual do sociólogo paulista como assegura Cândido: "De fato, ela propiciou a passagem de Florestan Fernandes para a investigação de situações sociais proble- 
máticas, quando até então ele se havia ocupado sobretudo com trabalhos de reconstrução histórica por meio da análise bibliográfica, tendo limitado a pesquisa empírica quase apenas a manifestações folclóricas" (Cândido, 1992, p.26).

Livre-docente em 1953, com a tese Ensaio sobre o Método de Interpretação Funcionalista na Sociologia, Florestan Fernandes ocupou com a volta definitiva de Roger Bastide à França a Cadeira de Sociologia I como titular:

Porque a passagem para a cadeira do Bastide se deu por iniciativa dele. Ele custou a voltar para a França porque madame Bastide queria que ele fosse para Paris e não para a província. Ele poderia ir para Bordéus que é uma faculdade muito importante, mais a madame Bastide não aceitou e, no fim, o professor Bastide foi de fato para Paris (...). O professor Bastide, num dado momento, 1952, viu que ou ele encerrava a carreira no Brasil ou ele não saía mais do Brasil. (...) Propõe ao Departamento de Sociologia e Antropologia que ele deveria ter uma pessoa que pudesse ser o seu substituto e que, do ponto de vista dele, quem poderia substituí-lo era eu. (Depoimento concedido a Eliane Veras Soares em 23/05/1991)

\section{Maria Isaura Pereira de Queiroz: intérprete da cultura brasileira ${ }^{20}$}

Tratar do pensamento de Roger Bastide, sem fazer referência ao incessante trabalho de análise e divulgação de sua obra realizado por Maria Isaura Pereira de Queiroz, não é possível. Principal herdeira intelectual de Bastide nos termos lembrados por Beylier ${ }^{21}$, Maria Isaura considera que o sociólogo francês, em seu diálogo constante com os pensadores brasileiros das décadas anteriores como Nina Rodrigues, Euclides da Cunha, Manuel Querino e Gilberto Freyre, pôde formular uma nova visão da sociedade brasileira:

Uma visão nova, uma visão dinâmica da sociedade brasileira se irradia de seus trabalhos, que não havia sido atingida pelos antecessores, muito embora alguns tenham procurado estudá-la através da história. Esta visão dinâmica que ele inaugura, Roger Bastide transmitiu-a aos discípulos, juntamente com tudo quanto havia conservado das interpretações tomadas aos sociólogos 
nacionais seus antecessores. Torna-se assim o elo de ligação entre sociólogos brasileiros da fase anterior e sociólogos posteriores. (Pereira de Queiroz, 1977, p.1360)

Bastide transmitiu essa visão dinâmica da sociedade brasileira aos seus alunos que procuraram em suas pesquisas entender a sociedade brasileira em toda a sua complexidade. Para Maria Isaura, Bastide foi o elo de ligação entre duas gerações de sociólogos brasileiros porque não é possível diferenciar uma de outra sem se remeter aos trabalhos de Bastide que se tornaram "ponto de referência magno para a compreensão do evoluir das interpretações" (Queiroz, 1977, p.1361).

Ao ingressar no curso de ciências sociais da Faculdade de Filosofia, Ciências e Letras da Universidade de São Paulo em 1946, Maria Isaura tomou conhecimento da orientação que predominava na formação dos alunos. Como a Faculdade de Filosofia, Ciências e Letras estava instalada naquela época no Instituto de Educação Caetano de Campos na Praça da República, onde Maria Isaura estudou desde o jardim de infância, esta sentiu a diferença somente no momento da avaliação:

A estranheza surgiu no momento em que foram solicitados os primeiros trabalhos de aproveitamento: uma pesquisa teórica - 'A Sociologia de Augusto Comte' - ; uma pesquisa de observação direta com seu respectivo relatório, sobre a Congregação Cristã do Brasil, seita protestante sediada no Brás. Foi então que me dei conta de que penetrara noutro nível de raciocínio e de exigências, num outro nível intelectual. (Queiroz, 1990, p.11) $)^{22}$

Percebera que a orientação do curso consistia, além dos objetivos iniciais que eram, na formação de professores para o ensino secundário e na melhoria da qualificação da elite dirigente, também a formação de cientistas.

Os dois trabalhos citados constituem exemplos do que então se demandava dos estudantes: compreensão em profundidade dos textos lidos, com dissertação que comprovasse as operações do espírito e redundasse em conclusões fundamentadas; exercício da técnica sociológica para aprender a captar o real, seguido de relatório claro e detalhado. $\mathrm{O}$ curso se iniciava, pois, exercitando duas vertentes em que nos especializaríamos durante quatro anos: a reflexão teórica; a coleta de material e sua análise. A tônica do 
curso apontava, assim, para a formação do cientista e do pesquisador. (Queiroz, 1990, p.11)

A formação de cientistas e pesquisadores, apesar de não ser a orientação inicial da Faculdade de Filosofia, Ciências e Letras, acabou por se impor devido principalmente ao trabalho dos professores europeus, admite Maria Isaura. Entre estes, estava Bastide de quem Maria Isaura logo se tornou aluna e depois discípula. Assim como Gilda de Mello e Souza, Maria Isaura, antes de começar o curso de ciências sociais, teve uma experiência na ficção iniciada na infância conforme nos relata Eva Blay: "A obra da professora Maria Isaura tem a marca da escritora. Suas primeiras publicações apareceram em 'O Tico-Tico', quando ela tinha oito anos de idade. Escreve desde então ininterruptamente. Passou para os contos juvenis e para os escritos acadêmicos. Suas cartas são deliciosas formas de diálogo acadêmico e de amizade" (Blay, 1990, p.8).

Consideramos que isto deve ter favorecido em certa medida uma aproximação maior entre Bastide e Maria Isaura, a exemplo do que ocorreu em relação à Gilda de Mello e Souza. O interesse de Bastide pela literatura e o seu respeito pelos próprios interesses de seus alunos se conjugavam e permitiam uma identificação maior na relação entre o mestre e seus discípulos. Concluída a licenciatura em ciências sociais em 1949, Maria Isaura pouco depois se tornou orientanda e assistente de Bastide na Cadeira de Sociologia I. Em 1956, obteve o diploma de doutorado na École Pratique des Hautes Études com a tese La Guerre Sainte au Brésil: Le Mouvement Messianique du Contestado, cuja banca examinadora foi composta por Claude Lévi-Strauss, Gabriel Le Bras e Roger Bastide.

As pesquisas sobre os movimentos messiânicos consistiram no foco central da atenção de Maria Isaura desde o seu curso na USP, conforme ela assinalou posteriormente. O incentivo de Roger Bastide é reconhecido no prefácio de seu livro $O$ Messianismo no Brasil e no Mundo: "Se pude reunir cabedal de tal vulto, foi porque contei com o auxílio e a generosidade de diversos professores e amigos. Quero mencionar em primeiro lugar, e com o maior destaque, o professor Roger Bastide, meu Mestre, que não só contribuiu em larga medida para que bibliografia se fosse tornando cada vez mais extensa, como também me deu o apoio necessário e a crítica justa nos momentos em que deles precisei" (Queiroz, 1965: XI). 
Seu interesse pelo messianismo se desdobrou mais tarde, já nos anos 60 , nos estudos sobre o campesinato brasileiro com a formulação do conceito de grupos rústicos. Seguindo a trilha do mestre francês, Maria Isaura dedicou-se a vários campos, entre eles a sociologia da religião, a sociologia política, a sociologia rural e a sociologia da cultura. ${ }^{23}$ Florestan Fernandes destacou a amplitude e a diversidade da obra de Maria Isaura bem como o seu reconhecimento em relação a Bastide: "Honrou sempre os seus compromissos com o mestre comum Roger Bastide. E nunca se refugiou em qualquer nicho acadêmico." ${ }^{24}$

Tais características podem ser encontradas na trajetória intelectual de Maria Isaura e na sua obra. Influenciada por Roger Bastide, Maria Isaura também sempre defendeu a necessidade de utilizar diferentes métodos de investigação e análise não importando se eram reconhecidos como pertencentes a outras disciplinas ou teorias rivais. Acredita Maria Isaura que a realidade é que indica o método mais apropriado para que o pesquisador possa melhor conhecê-la, e não o contrário. ${ }^{25}$ Maria Isaura, diferentemente dos cientistas sociais de sua geração fez outras escolhas temáticas. Por outro lado, aproxima-se em grande medida dos mesmos pelo mesmo rigor analítico na elaboração de suas pesquisas. Para Glaucia Villas Bôas (1994), as escolhas teóricas, metodológicas e temáticas de Maria Isaura devem ser compreendidas a partir da produção das ciências sociais nos anos 40, 50 e 60 .

Nesse período, principalmente na década de 50 , as ciências sociais vão se voltar para o estudo da vida socioeconômica em seus vários níveis, com maior destaque às mudanças e desigualdades sociais. A sociologia, em particular, tem o objetivo de formular padrões de trabalho científico baseados em princípios universais da ciência. Villas Bôas considera que os estudos de Maria Isaura Pereira de Queiroz sobre o messianismo, os cangaceiros e o mandonismo local que englobam ao mesmo tempo a sociologia, a história e a antropologia mediante a construção de uma ponte entre o passado e o presente lhe conferem uma posição peculiar em sua geração. Maria Isaura, como o mestre francês, não recusava os estudos dos pensadores brasileiros anteriores. Ao contrário, realiza uma leitura crítica e atenta das contribuições desses autores, procurando ver tanto os seus aspectos positivos como também as suas limitações para a compreensão da sociedade brasileira.

Portanto, Maria Isaura não faz distinção de antemão entre as fontes que possam ser utilizadas na pesquisa, pois entende que todas 
são essenciais para o estudo minucioso dos fenômenos abordados, desde que sejam conhecidas as suas limitações e os seus prováveis usos. Segundo Villas Bôas, o caminho sociológico escolhido por Maria Isaura, na verdade, está direcionado para a busca da cultura brasileira em todas as suas dimensões.

Maria Isaura pode ser considerada uma intérprete da cultura brasileira como foram em grande medida os outros cientistas sociais de sua geração. O que os diferencia reside na escolha de objetos e de procedimentos para refletir sobre estes e que os aproxima é o estilo de reflexão, a formação comum baseada em um espírito crítico. Para Maria Arminda Arruda (1994), "há uma similitude na linguagem, do uso da noção correta, na resolução do problema conceitual e da harmonia entre a atividade de investigação, a formulação conceitual e a exposição de um estilo" entre os membros da geração de Maria Isaura. Procuraram aliar o olhar universal e o recorte particular dos temas abordados com o objetivo final que era a interpretação da cultura brasileira.

\section{Considerações Finais}

Os cientistas sociais brasileiros, ao tratar da reflexão sobre a memória de suas disciplinas e da sua produção intelectual, precisam adotar uma perspectiva comparativa. Ou melhor, as reformulações sobre a produção intelectual, tanto dos primeiros pensadores nacionais, como dos cientistas sociais estrangeiros e brasileiros das últimas décadas devem ser analisadas considerando o contexto histórico-social e econômico existente no Brasil e nos outros países. Precisamos romper com o "etnocentrismo às avessas" ainda presente em vários estudos e valorizar a efetiva contribuição dos cientistas sociais nacionais e estrangeiros. Em suma, não precisamos hoje insistir nas identidades de cada disciplina. Ao contrário, talvez seja possível, conforme foi destacado por Mariza Peirano (1991), dar ênfase a um pluralismo renovado, pois o resgate deste nas ciências sociais coloca-se atualmente como extremamente positivo.

Dessa forma, o presente artigo procurou mostrar nos depoimentos, nas trajetórias e nas idéias dos ex-alunos de Bastide, Antônio Cândido, Florestan Fernandes e Gilda de Mello e Souza, o perfil de um professor, um pesquisador e um pensador preocupado em incentivar o pluralismo 
de idéias e o respeito às diferenças, o que com certeza contribuiu para um estilo brasileiro de ciências sociais, bem diferenciado dos demais. Nos cursos, nas pesquisas, no convívio dentro e fora da universidade, Bastide se caracterizou pelo pensamento humanista e plural que Florestan Fernandes melhor definiu: "Sua posição relativista e pluralista não se reduzia a uma fuga ou a um pacto de concessões e conciliações. A verdade ou verdadeiro subiam à tona com delicadeza, permitindo que o outro descobrisse por auto-esclarecimento as máscaras ou as mistificações ocultas através de seus ídola” (Fernandes, 1995, p.89).

$\mathrm{Na}$ análise da recepção e do impacto das idéias bastidianas entre seus ex-alunos, foi possível perceber que a visão relativista e pluralista esteve sempre presente. Conforme as diferenças existentes entre seus alunos, estabeleceu relações de colaboração, interlocução e orientação, percebendo e respeitando com sensibilidade as especificidades de cada um.

Bastide em essência defendeu uma concepção democrática da ciência na qual podiam conviver trajetórias intelectuais em muitos aspectos distintas como as de Antônio Cândido, Florestan Fernandes, Gilda de Mello e Souza e Maria Isaura Pereira de Queiroz: "O legado de Bastide vai em outra direção. A cidadela da ciência social não fecha os seus portões a ninguém nem estimula o estabelecimento de uma corte de serviçais enterrados em tarefas circunscritas e intransponíveis. Restabelece-se, em todo o vigor, a essência democrática da ciência, mais evidente na área experimental. Os cruzados não o são do grande mestre, mas do saber científico" (Fernandes, 1995, p.91).

Há exatamente 28 anos Roger Bastide falecia na França. Seu pensamento continua presente assim em ex-seus alunos, mesmo que seu nome e seu lugar no campo acadêmico e científico tenham se reduzido ou até mesmo sido relegados às estantes mais escondidas das ciências sociais nas últimas décadas. Atualmente, tanto no Brasil como na França, as idéias de Bastide estão sendo retomadas pouco a pouco, o que poderá contribuir para a continuidade de sua recepção nas ciências sociais. 


\section{Depoimentos}

- Depoimento a Eliane Veras:

Florestan Fernandes, Brasília, 23 de maio de 1991.

- Depoimentos a Maria Lúcia de Santana Braga:

Florestan Fernandes, Brasília, 03 de maio de 1994.

Antônio Cândido, São Paulo, 26 de maio de 1994.

Gilda de Mello e Souza, São Paulo, 26 de maio de 1994.

\section{Notas}

1 O presente texto foi apresentado originalmente como capítulo da dissertação de mestrado intitulada A Sociologia Pluralista de Roger Bastide: um itinerário, defendida em 1994 no Programa de Pós-graduação do Departamento de Sociologia/UnB. No momento, a autora está concluindo sua tese de doutorado, na qual dá continuidade ao estudo da recepção de Roger Bastide no Brasil.

2 A "Semana Roger Bastide" foi promovida pelo Centro de Estudos Rurais e Urbanos e Instituto de Estudos Brasileiros da Universidade de São Paulo. Os estudos e depoimentos apresentados durante a semana foram publicados na Revista do Instituto de Estudos Brasileiros em 1978.

3 Entrevista concedida a Mariza Peirano em novembro de 1978 e citada em seu artigo "O Pluralismo de Antônio Cândido". In: Peirano, Mariza G. S. Uma Antropologia no plural: três experiências contemporâneas. Brasília, Editora da UnB, 1992, p. 35 .

4 Esse artigo traçou um quadro amplo do ensino de sociologia em São Paulo nos anos 30 e 40 e foi publicado no Boletim del Instituto de Sociologia da Facultad de Filosofia y Letras de la Universidad de Buenos Aires, número 4, 1945.

5 Roger Bastide, durante os dezesseis anos que ensinou no Brasil, foi professor de inúmeras turmas que passaram pela USP. Também, podemos citar ainda no início dos anos 40 , que foram seus alunos e se tornaram renomados cientistas sociais, Paulo Emílio Salles Gomes que se orientou para o cinema e Oswaldo Elias Xidieh para a cultura popular. Gioconda Mussolini, Lavínia Costa Vilela, 
Lucila Hermann e Mario Wagner Vieira da Cunha, além de alunos, foram assistentes de Bastide. Já no final da década de 40, também foram alunos de Bastide, Fernando Henrique Cardoso, Octávio Ianni, Maria Sylvia de Carvalho Franco e Aziz Simão.

6 O tópico a seguir utilizará principalmente os dados presentes no depoimento de Gilda de Mello e Souza, concedido à autora em 26/ 05/1994, e já citado anteriormente.

7 Roger Bastide, em entrevista concedida a Irene Cardoso em 18/ 08/73 e publicada na Revista Discurso $n^{\circ} 16,1987$, lembra sobre o episódio da saída de Lévi-Strauss que houve alguns problemas entre este e os dirigentes da universidade: "Acho que foi bom funcionário, mas escreveu artigos, fez discursos no momento da Frente Popular dentro de $O$ Estado, cobrando de Mesquita o fato de ter feito ataques no jornal contra a Frente Popular. O Estado foi contra a Frente Popular e Lévi-Strauss se zangou, se irritou. Não houve briga, mas houve separação. E quando ele foi fazer sua pesquisa entre os índios, pediram-me para tomar seu lugar. Eu não sabia disso, porque estava longe do Brasil e aceitei. E depois soube, muito bem, que fui chamado porque algumas pessoas não desejavam que Lévi-Strauss voltasse a Faculdade. (...) Fui muito mal recebido aqui no Brasil pelos professores franceses, menos Arbousse, que era muito ligado a Mesquita; fui muito mal recebido por Monberg e outros. E muito mal recebido pelos alunos, muito mal." (Bastide, 1987, p.190)

8 Paul Arbousse-Bastide, amigo e também professor da USP no mesmo período em que Bastide esteve aqui, relata que este apesar de sua formação em filosofia sempre se interessou pela literatura. Revela, inclusive, que Bastide, seu colega durante o serviço militar na França, escreveu um poema em 1920 intitulado "A Escalada do Deserto". Essas passagens são citadas por Beylier (1977), que interroga se Bastide não cogitou em algum momento dedicarse à literatura.

9 A 1. ${ }^{a}$ edição do livro Arte e Sociedade de Bastide, editada em 1945, foi traduzida por Gilda de Mello e Souza. Bastide, apesar de ter vivido dezesseis anos no Brasil, não conseguiu aprender a língua portuguesa o suficiente e, por isso, escrevia em francês os seus textos que depois eram traduzidos para o português. 
10 A $1^{\mathrm{a}}$ edição foi publicada em 1978 pela Companhia de Letras com o título $O$ espírito das roupas: a moda do século XIX com pequenas modificações na estrutura e redação do texto, mas com a manutenção integral do trabalho. Na apresentação do trabalho, Gilda de Mello e Souza lembra a atualidade de sua tese que nos anos 50 pareceu fútil a muita gente.

11 Os depoimentos de Antônio Cândido citados nesse tópico foram colhidos pela autora em 26/05/1994.

12 Antônio Cândido em seu depoimento sobre esse aspecto pretendeu desfazer uma interpretação equivocada da entrevista concedida por Bastide em 1973, já citada aqui, na qual deu a entender que os professores franceses eram contrários à pesquisa. Acreditamos que o mal-entendido ocorreu porque Bastide nessa entrevista específica disse que nos seus primeiros anos no Brasil não foi possível fazer pesquisa devido à guerra na Europa e à falta de verbas. Segundo ele: "Tentei desenvolver o gosto pela pesquisa nos estudantes. Mas não me era possível sair com eles, ir ao interior fazer pesquisa... Só de vez em quando passava dois dias com eles no interior ou no sul. Não havia verbas." (Bastide, 1987, p.194)

13 Há um episódio relatado por Antônio Cândido que demonstra de forma clara a energia infindável de Bastide: "Era um trabalhador infatigável. Ele dizia que trabalhava para não ficar louco. Eu sei que uma vez ele alugou uma casa em Poços de Caldas, foi cliente do meu pai. E eu fui visitá-lo e ele não estava. $\mathrm{Na}$ verdade, ele estava. Ele ficava escondido no escritório estudando e madame Bastide dizia que não estava. Nunca ele estava. Madame Bastide fazia barreira: o professor está muito bem porque ele está podendo descansar bastante. Ele não tem trabalhado mais do que sete ou oito horas por dia. Este era o descanso dele."

14 Esse ensaio de Bastide é considerado por Cândido como precursor devido à sua alta qualidade e à sua abordagem inovadora que incorpora ao mesmo tempo a análise biográfica, psicológica, sociológica e do discurso. Ver Roger Bastide, "Machado de Assis, paisa-

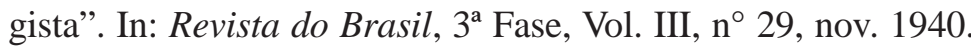

15 Eliane Veras Soares defendeu em 1993 no Programa de Pósgraduação em Sociologia da Universidade de Brasília a dissertação de mestrado Florestan Fernandes: o militante solitário, poste- 
riormente publicada pela Editora Cortez em 1997. Em sua dissertação, Eliane Veras analisa a trajetória política de Florestan Fernandes por meio da reconstituição de sua história de vida. Para isso, coletou vários depoimentos com o sociólogo e deputado paulista pelo Partido dos Trabalhadores que serão aqui utilizados conforme o objetivo de nosso trabalho.

16 Como Florestan havia vivido em vários bairros de São Paulo, ele conhecia de perto o material que, aliando com as leituras de antropólogos e sociólogos, lhe deu condições de fazer uma análise mais sofisticada do folclore, conforme pode ser verificado nos depoimentos a Eliane Veras e à autora.

17 Até aquele momento, Bastide e Florestan tinham tido contato em sala de aula e também por meio de um pequeno trabalho feito por Florestan sobre biografia de pais de santo negros em São Paulo, encomendado por Bastide. Esse pequeno trabalho, segundo Florestan, já tinha dado de certa forma a Bastide uma idéia de seu potencial intelectual.

18 Fernando de Azevedo, professor da Cadeira de Sociologia II, ofereceu ajuda financeira e acadêmica na época para Florestan que recusou. O professor Paul Hugon, com quem Florestan havia feito um trabalho sobre a evolução do comércio exterior no Brasil, também o convidou para ser seu assistente assim que terminasse o curso e para fazer o doutorado com a sua orientação. Ver Florestan Fernandes, op. cit., 1977, p. 160-163.

19 Os professores Paul Hugon de economia política e Eduardo Alcântara de Oliveira de estatística também convidaram Florestan para ser assistente.

20 Maria Isaura Pereira de Queiroz foi a única ex-aluna de Bastide presente neste artigo a não conceder depoimento à autora. Segundo Maria Isaura, o que ela pode dizer sobre a sua relação com Bastide como aluna, colaboradora e divulgadora de sua obra, encontra-se nos seus artigos e livros já publicados sobre o mesmo. Eva Blay (1990), em discurso proferido na sessão solene da Congregação da Faculdade de Filosofia, Letras e Ciências Humanas da USP que outorgou o título de Professora Emérita à Maria Isaura Pereira de Queiroz, lembrou que esta não concede entrevistas ou depoimentos, porque acredita que seu espaço é unicamente o intelectual. 
21 Charles Beylier em conferência na V jornada de Estudos sobre a obra de Maria Isaura Pereira de Queiroz realizada pela UNESP em Marília, São Paulo, agosto de 1994 , afirmou: "Além disso, não há no Brasil e na França uma pessoa que conhece tanto Roger Bastide como Maria Isaura. Ela foi assistente e colaboradora, após ter sido aluna de Roger Bastide. Maria Isaura organizou vários encontros, traduziu e mandou traduzir muitos livros e atualmente ela é a herdeira intelectual de Roger Bastide."

22 Maria Isaura em seu discurso de agradecimento na sessão solene da Congregação da Faculdade de Filosofia, Letras e Ciências Humanas da USP que lhe outorgou o título de Professora Emérita em 31 de maio de 1990 fez um pequeno balanço de sua trajetória intelectual.

23 Blay (1990) compreende a obra acadêmica de Maria Isaura dividida em três períodos: o primeiro que abarca os seus estudos sobre a reforma e revolução analisadas através dos movimentos messiânicos e do mandonismo na política. O segundo refere-se aos estudos rurais que se consolidou com a fundação do Centro de Estudos Rurais e Urbanos (CERU) em 1964. E o terceiro período abrange as pesquisas sobre a cultura brasileira com a análise da produção acadêmica e recentemente do carnaval, entre outros.

24 Carta de Florestan Fernandes enviada à organização da V Jornada de Ciências Sociais dedicada à obra de Maria Isaura Pereira de Queiroz ocorrida de 22 a 26/08/94 na Universidade Estadual Paulista (Unesp), Marília, São Paulo. As outras jornadas foram dedicadas a Florestan Fernandes em 1986, a Caio Prado Júnior em 1988, a Antônio Cândido em 1990 e a Octavio Ianni em 1992.

25 Blay (1994) em conferência na V Jornada de Estudos lembrou que "Maria Isaura nunca se deteve em modelos. Maria Isaura foi pioneira nessa questão porque ela nunca se deteve em modelos. Quando estava no auge a utilização do modelo marxista, ela se rebelava embora tivesse fortes influências marxistas. Quando estava no auge o estruturalismo, ela também se rebelava porque mostrava a necessidade de nós utilizarmos diferentes métodos de investigação, de análise e de interpretação. Isto fez com que ela criasse um espaço próprio muito polêmico (...) Aquilo mexia muito com a nossa cabeça e foi muito positivo porque foi a única maneira 
de compreender que não é através de um único método que se consegue explicar a realidade social."

Abstract. The article analyses the reception of the thought of Roger Bastide in Brazil, during almost two decades, between 1938 and 1954. Bastide, as a teacher, a researcher and a thinker, established different relationships with his contemporaries and his pupils. This essay calls attention to the impact and the importance of Bastide's thoughts in the country, especially in four ex-pupils and Brazilian social scientists: Antônio Cândido, Florestan Fernandes, Gilda de Mello e Souza e Maria Isaura Pereira de Queiroz.

Résumé. Cet article a comme but analyser la pensée de Roger Bastide au Brésil pendant presque deux décennies, de 1938 à 1954. Bastide en tant que professeur, chercheur et penseur, a établi de différents types de rapports aves ses contemporains et ses élèves. Pour comprendre l'importance et la repercussion de ses idées dans notre pays on analysera ses rapports avec quatre anciens élèves et scientifiques sociaux renommés: Antônio Cândido, Florestan Fernandes, Gilda de Mello e Souza e Maria Isaura Pereira de Queiroz.

\section{Referências Bibliográficas}

Arruda, Maria Arminda do Nascimento (1994). A Contribuição teórica de Maria Isaura Pereira de Queiroz às Ciências Sociais. Palestra proferida na V Jornada de Estudos Maria Isaura Pereira de Queiroz, Unesp, Marília, São Paulo.

BAstide, Roger (1940). "Machado de Assis, paisagista". Revista do Brasil, São Paulo, vol. 3, n 29.

(1945). Arte e sociedade. São Paulo: Martins.

e Azevedo, Fernando (1945). "La ensenanza de la Sociologia en San Pablo". Boletin del Instituto de Sociologia, Buenos Aires, $n^{\circ} 4$.

e Fernandes, Florestan (1955). Relações entre negros e brancos em São Paulo. São Paulo: Anhembi. 
Paulo: n. ${ }^{\circ} 16$.

(1987). "Entrevista". Revista Discurso, São

Beylier, Charles (1977). L'oeuvre brésilienne de Roger Bastide. Thèse de Doctorat de 3. ${ }^{\circ}$ Cycle. Paris, 2 volumes.

(1994). Maria Isaura Pereira de Queiroze Roger Bastide: a sociologia brasileira na França. Palestra proferida na V Jornada de Estudos Maria Isaura Pereira de Queiroz, Unesp, Marília, São Paulo.

Blay, Eva A (1990). "Discurso proferido pela Professora Doutora Eva Alterman Blay, chefe do Departamento de Sociologia" Outorga do Título de Professora Emérita a Maria Isaura Pereira de Queiroz, FFLCH, Departamento de Sociologia, São Paulo.

(1994). Depoimento sobre a ação e a obra de Maria Isaura Pereira de Queiroz. Conferência proferida na V Jornada de Estudos Maria Isaura Pereira de Queiroz, Unesp, Marília, São Paulo.

Braga, Maria Lúcia de Santana (1994). A Sociologia pluralista de Roger Bastide: um itinerário. Dissertação de Mestrado, Universidade de Brasília.

CÂndido, Antônio (1987). Os Parceiros do Rio Bonito: estudo sobre o caipira paulista e a transformação de seus meios de vida. São Paulo: Livraria Duas Cidades.

(1992). "A Faculdade de Filosofia no Centenário da Abolição". Novos Estudos CEBRAP, n. 34.

(1993). Recortes. São Paulo: Companhia das Letras.

Dauty, Denise (1985). Roger Bastide et le nouvel humanisme. Thése, Paris.

FERnANDES, Florestan (1961). Folclore e mudança social na cidade de São Paulo. São Paulo: Anhembi,.

(1977). A Sociologia no Brasil: contribuição para o estudo da sua formação e desenvolvimento. Petrópolis: Vozes.

(1994). Carta à organização da V Jornada de 
Estudos Maria Isaura Pereira de Queiroz. Unesp, Marília, São Paulo.

Ática.

(1995). A contestação necessária. São Paulo:

NogueIRA, Oracy (1978). "Evocação de Bastide". Revista do Instituto de Estudos Brasileiros, São Paulo.

Peixoto, Fernanda (2000). Diálogos brasileiros: uma análise da obra de Roger Bastide. São Paulo: Editora da Universidade São Paulo.

Peirano, Mariza G. S (1991). "Por um pluralismo renovado". In: Bomeny, Helena e Birman, Patrícia (orgs.). As assim chamadas Ciências Sociais: a formação do cientista social no Brasil. Rio de Janeiro, UERJ: Relume Dumará.

(1992). Uma Antropologia no plural: três experiências contemporâneas. Brasília: Editora UnB.

Pereira de QueIroz, Maria Isaura (1965). O messianismo no Brasil e no mundo. São Paulo: USP.

(1977). "A Sociologia brasileira na década de 40 e a contribuição de Roger Bastide". Ciência e Cultura, 29 (12), dezembro.

(1978). "Uma nova interpretação do Brasil: a contribuição de Roger Bastide à Sociologia Brasileira". Revista do Instituto de Estudos Brasileiros, São Paulo. (org.) (1983). Roger Bastide. São Paulo: Ática.

(1989). O Brasil dos cientistas sociais não brasileiros. Caxambu, XIII Encontro Anual da Anpocs.

(1990). "Discurso de agradecimento proferido pela Professora Maria Isaura Pereira de Queiroz". In: Outorga do Título de Professora Emérita a Maria Isaura Pereira de Queiroz, FFLCH, Departamento de Sociologia, São Paulo.

(org.) (1993). O Imaginário em terra conquistada. São Paulo: CERU.

Ravelet, Claude (1978). Phénomenologie du sacré: essai sur l'antropologie interculturelle de Roger Bastide. Thèse de 3. ${ }^{\circ}$ Cycle, Paris. 
SouzA, Gilda de Mello e (1987). O espírito das roupas: a moda no século dezenove. São Paulo: Companhia das Letras.

SoAres, Eliane Veras (1997). Florestan Fernandes: o militante solitário. São Paulo: Cortez.

Villas BôAs, Glaucia (1994). A contribuição teórica de Maria Isaura Pereira de Queiroz às Ciências Sociais. Palestra proferida na V Jornada de Estudos Maria Isaura Pereira de Queiroz, Unesp, Marília, São Paulo. 